\title{
Patient Provider Interaction: Important Aspect of Anti-Tuberculosis Treatment Adherence in E Ward of Mumbai Municipal Corporation
}

\author{
Khedkar Sudam ${ }^{1}$, Kulkarni Priya Y2 $^{*}$ Akarte S V 3 \\ ${ }^{1}$ Assistant Professor, Department of Medicine, MIMER Medical College, Talegaon, Pune, Maharastra, India. \\ $2^{\star}$ Associate Professor, Department of Community Medicine, SMBT Medical College, Nasik, Maharastra, India. \\ ${ }^{3}$ Professor and Head, Department of Community Medicine, Grant Medical College, Mumbai, Maharastra, India.
}

\begin{abstract}
Background: Treatment non-adherence is a major challenge before tuberculosis (TB) control activities. Treatment adherence is affected by various factors that can be patient related, provider related or system related.

Objective: To study patient provider interaction and its effect on treatment adherence among new sputum smear pulmonary tuberculosis patients treated at Directly observed treatment short course (DOTS) centres run by government.

Materials and Methods: New smear positive pulmonary TB patients initiated on category I regimen of DOTS in first two quarters of a calendar year at 24 DOTS centres and completed at least intensive phase $(\mathrm{N}=118)$ in E-ward of Mumbai Municipal Corporation (MMC) were interviewed using pretested semi-structured schedule, which was designed to elicit socio-demographic factors and patient provider interaction. Treatment cards were screened for treatment adherence after any final outcome as per RNTCP guidelines.

Results: Treatment adherent patients were $61 \%$ (72/118) and $39 \%$ (46/118) were treatment non-adherent. Amomg 18.6\% ( 22/118) patients PPI was satisfactory to full extent, while among $28.8 \%$ (34/118) PPI was unsatisfactory. Satisfactory PPI was associated with treatment adherence $(p<0.0001$, OR= $3.238,95 \% \mathrm{Cl}=1.746-6.005)$.
\end{abstract}

\section{INTRODUCTION}

Tuberculosis (TB) remains one of the world's deadliest communicable diseases. In 2013, an estimated 9.0 million people developed TB. However, given that most deaths from TB are preventable, the death toll from the disease is still unacceptably high. Efforts to combat TB morbidity and mortality, must be accelerated if 2015 global targets, set within the context of the Millennium Development Goals (MDGs), are to be met. ${ }^{1}$

Anti-tuberculosis treatment (ATT) has duration of at least 6 months; multiple drugs with unpleasant side effects make the patients prone to be non-adherent. It contributes increased morbidity, mortality, cost and duration of ATT and most importantly increases drug resistance at individual and community level. 2,3

ATT adherence helps to achieve desired treatment success and help to minimize emergence of drug resistant strains. Treatment adherence is the extent to which patients' history of therapeutic
Conclusion: Providers need to give attention and sufficient time listening to patients and discussing about the disease. They need to be trained based on essential elements of patient provider interaction like establishing rapport, initiating full discussion of illness and treatment, etc. It will help to improve treatment adherence \& success rate.

Key words: NSP pulmonary tuberculosis, Treatment adherence, Patient provider Interaction/ communication.

\section{${ }^{*}$ Correspondence to:}

Dr Kulkarni Priya Y, M. D. (PSM),

Associate Professor,

Department of Community Medicine,

SMBT Medical College, Nasik,

Maharastra, India.

Article History:

Received: 29-09-2016, Revised: 21-10-2016, Accepted: 10-11-2016

\begin{tabular}{|l|c|}
\hline \multicolumn{2}{|c|}{ Access this article online } \\
\hline $\begin{array}{l}\text { Website: } \\
\text { www.ijmrp.com }\end{array}$ & Quick Response code \\
\hline DOI: & \\
10.21276/ijmrp.2016.2.6.020 & \\
\hline
\end{tabular}

drug intake coincides with prescribed treatment. It requires patients' agreement to providers' recommendations. ${ }^{2}$ And, it reflects active role of TB patients in self management of treatment and extent of patient provider interaction ${ }^{4}$ (PPI) that is how well provider has interacted with TB patients about his disease, treatment and its importance.

Treatment adherence is simultaneously influenced by several factors. They include individual patient characteristics, socioeconomic factors, the structure and nature of health care services offered, the quality of patient-provider communication, and the nature of social support that patients receive. ${ }^{5}$

Provider related characteristics associated with treatment adherence influence the quality of PPI and have an impact on patient behavior. The quality of providers' interpersonal skills has been shown to affect adherence. ${ }^{6}$ Positive outcomes may be more likely when physicians and providers make efforts to explain 
treatment regimens and address patient concerns ${ }^{7,8}$ Increased non-adherence has been noted in situations where providers appear insensitive, use medical jargon, view patients as complainers, or do not provide clear messages about the cause of the illness or reasons for treatment. ${ }^{9}$ Promoting PPI is among important strategies to promote ATT adherence. ${ }^{10,11}$

As DOTS providers are in direct contact with TB patients, ${ }^{12}$ with effective communication skills, they have important role in completion and success of ATT.

There is hardly any study investigated PPI among TB patients treated at DOTS centres specially in our study area. In the Present study, we tried to find out magnitude of satisfactory PPI, and its effect on treatment adherence among new smear positive (NSP) TB patients at treated at government health facilities that are Directly Observed Treatment Short-course (DOTS) centres.

\section{MATERIALS AND METHODS}

The study was carried out at 24 DOTS centres in E ward of Mumbai Municipal Corporation (MMC), in Maharashtra state of India. ATT is available at free of cost at DOTS centres as per revised anti-tuberculosis control program (RNTCP).

At the time of study period, MMC had a population of $>18$ million. For administrative purpose it is divided into 6 zones, each zone has $3-5$ wards named alphabetically. Zone 1 had 5 wards- $A, B, C$, $D$, and E. MMC had total 298 DOTS centres, 24 of them were located in $E$ ward. $E$ Ward had population of $>5$ lacs.

Ethical approval was obtained from Member secretary, Mumbai District TB control Society \& ethical committee of Grant Medical College \& J J Hospital. Verbal consent was taken from every patient before each interview.

All NSP TB patients $\geq 15$ years of age initiated on category I regimen of DOTS in first two quarters of a calendar year at 24 DOTS centres and completed at least intensive phase of ATT were recruited in the study assuming to give enough time to develop patient provider interaction. in E-ward of Mumbai Municipal Corporation (MMC) were interviewed using pre-tested semi-structured schedule, which was designed to elicit sociodemographic factors and patient provider interaction (PPI). Treatment cards were screened for treatment adherence after any final outcome as per RNTCP guidelines.

After verbal consent, study subjects were interviewed using pretested semi-structured interview schedule, translated into local language, to get socio-demographic information and information regarding PPI. Interview was carried out by trained interviewer at the DOTS centre when patients used to come weekly during continuation phase.

\section{Definitions used}

Patient: New Smear positive pulmonary tuberculosis patient initiated on category I ATT and completed at least intensive phase as per DOTS.

Provider: A government person or facility approached by the patient for relief from their health problem. ${ }^{13}$ As per RNTCP, they are called as DOTS provider.

Treatment adherent patient: Eligible patient who did not interrupt ATT any time for $>1$ month during the ATT course. ${ }^{14}$

Treatment non-adherent patient: Eligible patient who interrupted ATT any time during the course for $>1$ month. ${ }^{14}$

\section{Categorizaton of patient provider interaction}

It was assessed by two key parameters:

1. How diagnosis was revealed by provider to the patient.

2. Information given by provider about special diet, rest, precautions while coughing/sneezing/talking, about sputum disposal.

We assumed these two parameters to reflect PPI developed from start of the treatment. Table 1, shows 3 levels of satisfactory PPI we assumed in our study.

Table 1: Satisfactory level of patient provider interaction

\begin{tabular}{|c|c|c|c|}
\hline $\begin{array}{l}\text { Information given by the } \\
\text { centre staff }\end{array}$ & Satisfactory & $\begin{array}{l}\text { Satisfactory to } \\
\text { some extent }\end{array}$ & Unsatisfactory \\
\hline $\begin{array}{l}\text { Diagnosis revealed by the } \\
\text { provider to the patient }\end{array}$ & Yes & Yes & No \\
\hline $\begin{array}{l}\text { Provider told at the time of } \\
\text { diagnosis }\end{array}$ & $\begin{array}{l}\text { 1. You have TB } \\
\text { 2. It is fully curable by the treatment } \\
\text { 3. Take the treatment for at least } 6 \text { months }\end{array}$ & Any of 2 and 3 & $\begin{array}{l}\text { Take treatment for } 2-3 \\
\text { months then we will } \\
\text { again check sputum. }\end{array}$ \\
\hline Provider informed about & $\begin{array}{l}\text { All of: Special diet, rest, precautions while } \\
\text { coughing, sputum disposal. }\end{array}$ & $\begin{array}{c}\text { Any } 1 \text { or more but } \\
\text { not all. }\end{array}$ & None. \\
\hline
\end{tabular}

If the responses encountered from patient had any of unsatisfactory response (as per Table 1), PPI was considered as unsatisfactory.

It was considered as fully satisfactory if all responses encountered were of fully satisfactory category. Otherwise, PPI was considered as satisfactory to some extent.

For analysis purpose, only two categories are used satisfactory which includes fully satisfactory PPI \& PPI satisfactory to some extent and the other is unsatisfactory PPI. Treatment cards of the recruited patients were screened to determine treatment adherence after final outcome of ATT as per RNTCP. ${ }^{15}$

Data entry was done in Microsoft excel spreadsheet then imported to SPSS 15.0 (Statistical Package for the Social Sciences version 15.0, developed by IBM, Chicago USA in 2007.) data editor for further analysis.

Pearson's Chi squared test was used as test of significance for $2 * 2$ tables, when expected value is $>5$. When expected value in $2 * 2$ table was $<5$, Fisher's Exact test was used as a test of significance. When expected value in $n^{*} n$ table was $<5$, Likelihood Ratio test was used as a test of significance. 


\section{RESULTS}

We recruited 125 patients, out of them 5 could not be contacted, 2 refused to be interviewed. So, we studied PPI among 118 NSP TB patients and how it affected their treatment adherence.

$67.3 \%$ were males \& $32.7 \%$ were females. Median age of the patients was 30 years. Highest numbers of patients i.e. $31.2 \%$ were in the age group of $20-29$ years followed by $25.5 \%$ in the age group of $30-39$ years. $24.2 \%$ patients were illiterate, $49.2 \%$ patients had completed any of middle school standard. Only 3 patients were graduate \& all were males. $43.3 \%$ were unemployed. $58.8 \%$ of unemployed patients, excluding students \& housewives among unemployed, median duration of unemployment was 2 months ( $\min =1$ month, $\max =180$ months). Treatment adherent patients were 61\% (72/118) and 39\% (46/118) were treatment non-adherent. Amomg 18.6\% ( 22/118) patients PPI was satisfactory to full extent, while among $28.8 \%$ (34/118) PPI was unsatisfactory.

Patient provider interaction \& adherence/ non-adherence:

Satisfactory PPI was very highly significantly associated with treatment adherence $(p<0.0001, \quad O R=3.238,95 \% \mathrm{Cl}=1.746$ 6.005) (Table 2).

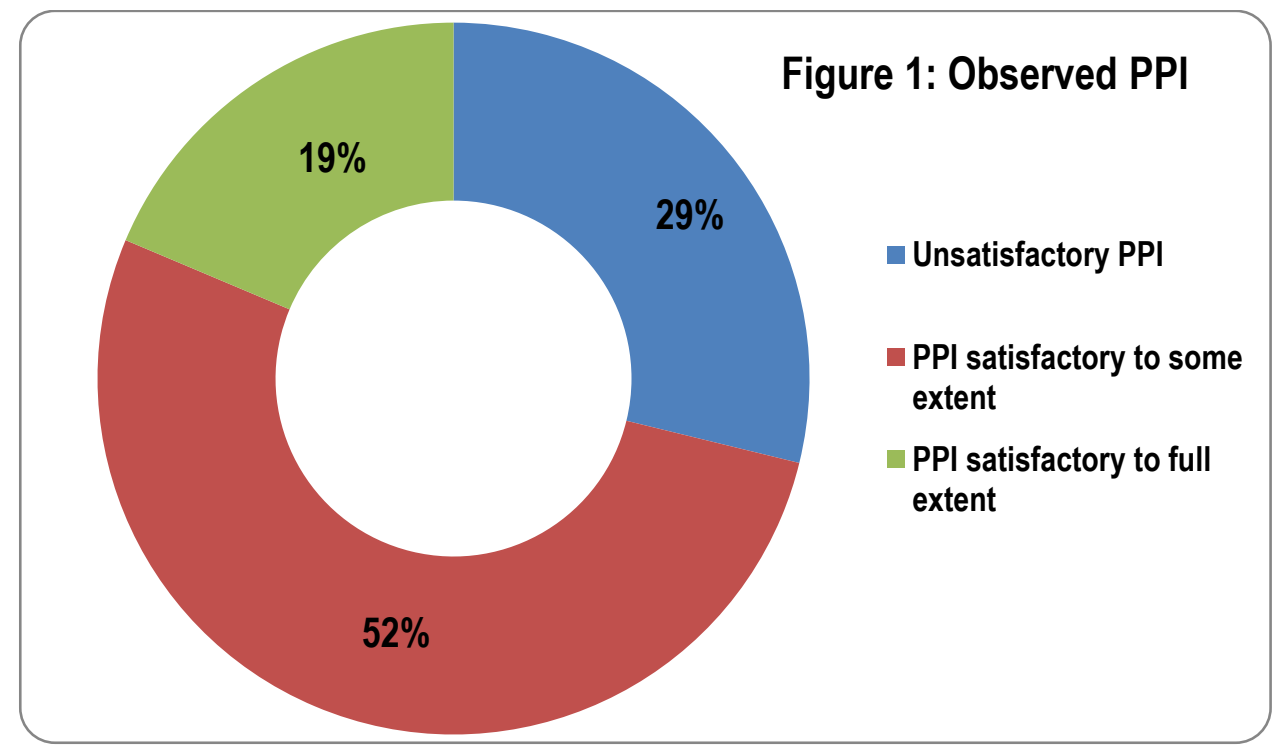

Table 2: PPI and adherent/ non-adherent status

\begin{tabular}{lccc}
\hline PPI & Adherent & Non-adherent & Total \\
\hline Satisfactory to some/ full extent & $64(76.2)$ & $20(23.8)$ & 84 \\
Unsatisafactory & $8(23.5)$ & $26(76.5)$ & 34 \\
Total & $72(61.0)$ & $46(39.0)$ & $118(100)$ \\
\hline
\end{tabular}

$X^{2}=28.218, d f=1, p<0.0001$

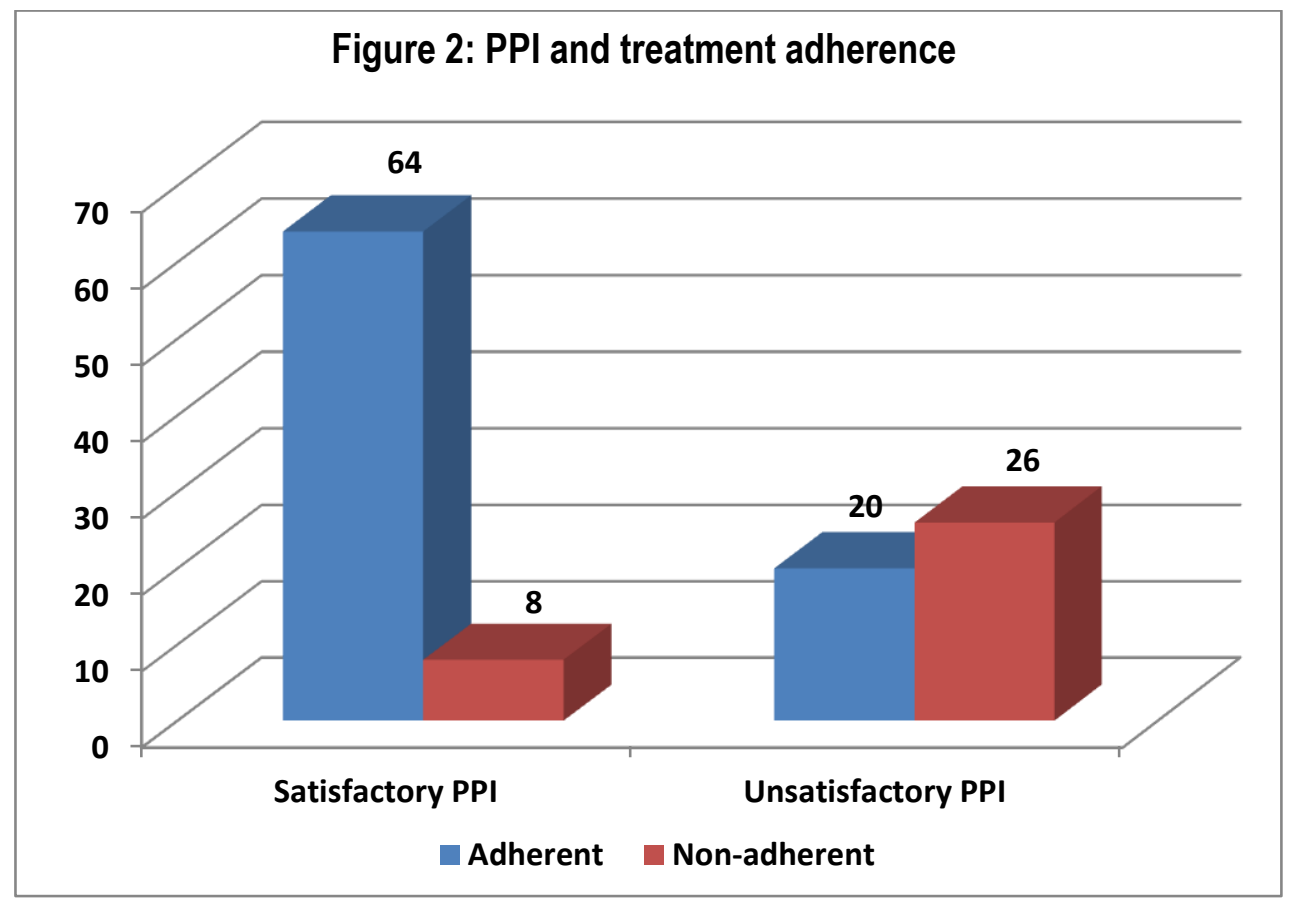


Diagnosis revealed \& advice received at that time:

In 112 (94.9\%) patients, provider revealed diagnosis but, 6 (5.1) told that provider didn't tell anything about diagnosis at start of treatment.

As shown in figure 3, category II of reveiling diagnosis to patients by the provider that TB was fully curable \& for they should take medicines for 6-7 months (category II) were significantly $(p<0.0001)$ more treatment adherent. $14(100 \%)$ out of 14 patients were non-adherent who were revealed their diagnosis by the provider as patient had TB \& take medicines for 2 months then they would see about duration of the treatment (category II).
Information given by center staff:

Out of 118 patients, $88(74.6 \%)$ were informed about special diet, $75(63.6 \%)$ were informed that rest was essential, $44(37.3 \%)$ were informed about precautions while coughing. Only 8 (6.8\%) patients received instructions about sputum disposal that patient should not spit anywhere other than at sanitation facility or in a separate jar. Out of 118 patients, 26 (22.0\%) were not informed about any of these things.

Thus, patients who were not informed about any of these things were significantly non-adherent with $\mathrm{OR}(\mathrm{OR}=2.490,95 \% \mathrm{Cl}=$ 1.680-3.691).

Table 3: Observed Categories of revealing diagnosis to the patient and its treatment adherence.

\begin{tabular}{|c|c|c|c|c|}
\hline $\begin{array}{l}\text { Category of } \\
\text { revealing } \\
\text { diagnosis to the } \\
\text { patient by provider }\end{array}$ & Diagnosis revealed as... & Adherent & Non-adherent & Frequency $(\%)$ \\
\hline $\mathrm{I}$ & You have TB and it is fully curable by medicines & $1(100)$ & 0 & $1(0.6)$ \\
\hline II & $\begin{array}{l}\text { You have TB \& take medicines regularly for 6-7 } \\
\text { months }\end{array}$ & $57(91.9)$ & $5(8.1)$ & $62(55.4)$ \\
\hline III & You have TB & $12(34.3)$ & $23(65.7)$ & $35(31.3)$ \\
\hline IV & Did not reveal diagnosis to the patient & $2(33.3)$ & $4(66.7)$ & $6(5.1)$ \\
\hline V & $\begin{array}{l}\text { You have TB, take medicines for } 2 \text { months then } \\
\text { we will see about duration of the treatment }\end{array}$ & 0 & $14(100)$ & $14(12.5)$ \\
\hline & Total & 72 & 46 & $118(100)$ \\
\hline
\end{tabular}

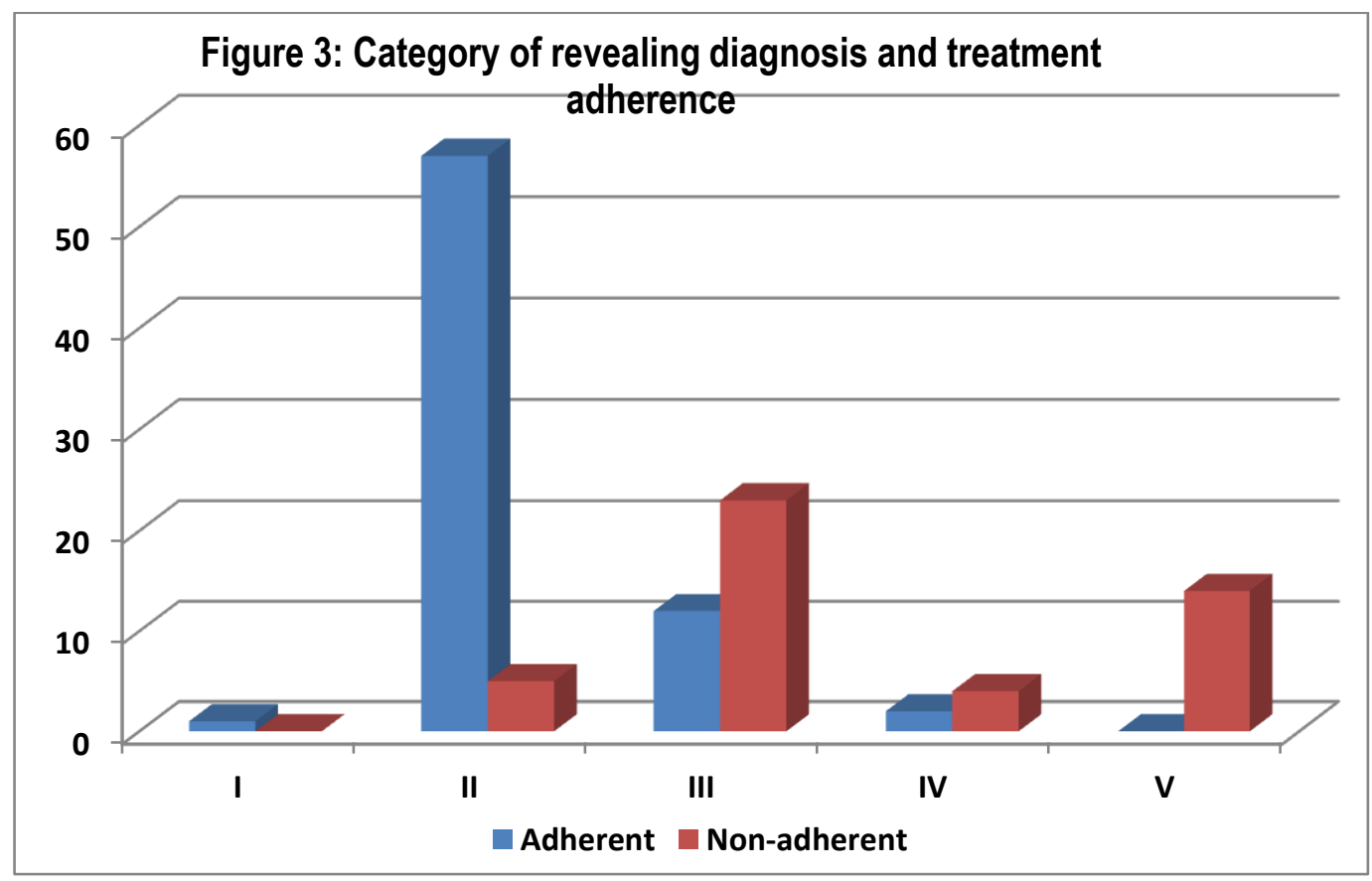

Table 4: Information given by centre staff and adherence:

\begin{tabular}{lccc}
\hline Patients informed about & Adherent & Non-adherent & Total \\
\hline None & $7(26.9)$ & $19(73.1)$ & 26 \\
At least one to all & $65(70.7)$ & $27(29.3)$ & 92 \\
Total & $72(61.0)$ & $46(39.0)$ & $118(100)$ \\
\hline
\end{tabular}




\section{DISCUSSION}

Doctor-patient communication during history taking or discussion about treatment plan, instructions given play important role in establishing a trusting PPI. It is, in turn becomes an important factor that leads to achieve appropriate information exchange between patient and provider and thus achieving desirable treatment results. ${ }^{6,16,17}$ The two parameters we considered are to assess whether adequate discussion was held with the patient about their disease.

Treatment adherence is seen as a chain of responsibilities, including patients' behaviour, health care workers' treatment/ communication with patients, and decision-makers' \& society's behaviour. ${ }^{18}$

Effective PPI plays important role of a bridge between patients and the system. Without their linkage, TB control activities remain unfruitful.

In the present study, among $18.6 \%$ patients a fully satisfactory PPI was developped denoting a significant attention and time given by the provider. But, $28.8 \%$ patients, either diagnosis was not revealed directly to the patient and/ or treatment plan was not informed well and/ or no other instruction were given to the patients. It was associated with very low treatment adherence among these patients.

Way of revealing diagnosis and advice given by the provider about the treatment of TB, also had effect on treatment adherence. Sevearl studies pointed out that adherent patients knew more about their diagnosis. For example, Wares D F et al (1998) identified, traced \& interviewed 30 non-adherent TB patients in Tara district, eastern Nepal \& equivalent adherent patients. Adherent patients knew more about their diagnosis $(p=0.007) .{ }^{18}$ Diagnosis was not directly revealed to $5.1 \%$ patients and majority of such patients (4/6) were treatment non-adherent. Reasons observed for not revealing diagnosis to the patients directly were patient would be frightened, might not come to take treatment, might get psychological trauma and providers did not have enough time to talk directly to patient etc. To remove the taboos associated with TB from patients themselves, provider can also be able to act as counsellor and should be trained accordingly.

Ashy Gad et al (1995) reported patients who received instructions about use \& importance of drugs from drug providers, patients with good knowledge about TB were more compliant. By Multivariate LRA knowledge about TB was one of the factors associated with increased compliance (OR= 8 87,4 85,3 19,2resp).

Information given by providers (Table 4) about TB helps to increase knowledge of the patients about TB and its treatment which have positive impact on treatment adherence. And also, it fosters communication between patient and provider.

$22 \%$ patients in our study received no any such information from provider and majority of them were treatment non-adherent. As magnitude of such information given by the provider increased, treatment adherence increased. Similarly, Sophia V et al (1997) observed more patients in adherent group received such information from providers than patients in non-adherent group.

We included NSP TB patients treated at government sector. Majority of patients approaching government sector for treatment are from socio-economically deprived class, same is true for our study subjects. PPI among patients treated at private sector may be different and needs to be studied.
Though, sample size in our study is limited, it throws light the extent of PPI in government sector and to highlights the need to strenghthen PPI under RNTCP.

PPI played important role in treatment adherence in our study. Providers need to give attention and sufficient time listening to patients and discussing about the disease. It is especially important among populations that stigmatize TB. ${ }^{9}$ Providers should be educated about relevant cultural beliefs and practices of the communities they serve, and should practice techniques for good communication with patients. ${ }^{20}$ Improved understanding and communication will help to identify and minimize barriers that patients and their families face. As a result, patients will be better able to adhere to treatment regimen. ${ }^{9}$

Essential elements of patient provider interaction are to establish rapport, initiate full discussion of illness and treatment, ask for relevant information using open-ended questions, summarize and clarify information as necessary, elicit patient's perspective on illness and treatment, offer information, negotiate the treatment plan. ${ }^{9}$ DOTS providers need to be trained and execute accordingly.

\section{REFERENCES}

1. WHO. Global TB report, 2014. World Health Organization: Geneva, Switzerland.

2. WHO. Disease specific reviews. Adherence to long term therapies: Evidence for action.2003: 123-8.

3. Pablos-Mendez A, Knirsch CA, Barr RG, Lerner BH, Frieded TR. Non-adherence in tuberculosis treatment: Predictors and consequences in New York city. Am J Med 1997;102:164-70.

4. Esther S. When TB treatment fails: A sociobehavioral account of patient adherence. Am Rev Respir Dis 1993; 147:1311-20.

5. World Health Organization, Adherence to Long-term Therapies: Evidence for Action. 2003, World Health Organization: Geneva, Switzerland.

6. Narenjiha M, Haghighat S, Bahaddor H, Shajari J, Jameie SB. The Importance of Physicians' Communication Skills on Patients' Satisfaction. Thrita J Med Sci. 2012;1(2): 57-61. DOI: 10.5812/thrita.5460

7. Stewart, M.A., Effective physician-patient communication and health outcomes: a review. Canadian Medical Association Journal, 1995. 152(9): p. 1423-33. 33.

8. Mead, N. and P. Bower, Patient-centred consultations and outcomes in primary care: a review of the literature. Patient Educ Couns, 2002. 48(1): p. 51-61.

9. Charles P. Felton National Tuberculosis Center: Adherence to Treatment for Latent Tuberculosis. Infection: A Manual for Health Care Providers. 2005. http://www.harlemtbcenter.org/Assets/web_docs/HarlemLTBI\%20Adherence6.pdf.

10. M'Imunya JM, Kredo T, Volmink J. Patient education and counselling for promoting adherence to treatment for tuberculosis. Cochrane Database Syst Rev. 2012;5:CD006591. [PubMed]

11. Liu Q, Abba K, Alejandria MM, Balanag VM, Berba RP, Lansang MA. Reminder systems and late patient tracers in the diagnosis and management of tuberculosis. Cochrane Database Syst Rev.2008;4:CD006594. [PubMed]

12. Central TB Division. Module for MPWs and other DOT providers, 2005. Central TB Division, DGHS, New Delhi. 
13. Selvam JM, Wares F, Perumal M, Gopi PG, Sudha G, Chandrasekaran $V$, et al. Health-seeking behaviour of new smearpositive TB patients under a DOTS programme in Tamil Nadu, India, 2003. Int J Tuberc Lung Dis 2007;11:161-7.

14. Sophia V, Balasangameshwara V, Srikantaramu N. Treatment dynamics and profile of patients under DTP: A prospective cohort study. Indian J Tuberc 1999;46:239-49.

15. Dye C, Garnett GP, Sleeman K, Williams BG. Prospects for worldwide tuberculosis control under the WHO DOTS strategy. Directly observed short-course therapy. Lancet 1998;352:1886-91. 16. Safran DG, Taira DA, Rogers WH, Kosinski M, Ware JE, Tarlov AR. Linking primary care performance to outcomes of care. J FamPract. 1998;47(3):213-20.

17. Stewart MA. Effective physician-patient communication and health outcomes: a review. CMAJ. 1995;152(9):1423-33.

18. Wares D F, Singh S, Acharya AK, Dangi R . Non-adherence to tuberculosis treatment in the Eastern tarai of Nepal.. Int $\mathrm{j}$ tuberc lung dis 2003;7(4):327-35.

19. Gad A, Mandii AMA, Sherif AARA, Gad ZM, Sallam S. Compliance with anti-tuberculosis drugd among TB patients in Alexandria. Egypt 1997;2:224-50.
20. Kulkarni PY, Akarte SV, Mankeshwar RM,Bhawalkar JS, Banerjee A, Kulkarni AD. Non-adherence of new pulmonary tuberculosis patients to anti-tuberculosis treatment. Annals of Medical and Health Sciences Research, 2013;3:67-74.

\section{Source of Support: Nil. Conflict of Interest: None Declared.}

Copyright: () the author(s) and publisher. IJMRP is an official publication of Ibn Sina Academy of Medieval Medicine \& Sciences, registered in 2001 under Indian Trusts Act, 1882.

This is an open access article distributed under the terms of the Creative Commons Attribution Non-commercial License, which permits unrestricted non-commercial use, distribution, and reproduction in any medium, provided the original work is properly cited.

Cite this article as: Khedkar Sudam, Kulkarni Priya Y, Akarte S V. Patient Provider Interaction: Important Aspect of AntiTuberculosis Treatment Adherence in $\mathrm{E}$ Ward of Mumbai Municipal Corporation. Int J Med Res Prof. 2016; 2(6):103-08. DOI:10.21276/ijmrp.2016.2.6.020 